\title{
Periapical abscess of a lower central incisor associated with a tongue piercing: A case report
}

Mehmet Oztel* and Paul G. Birch

Mehmet Oztel* and Paul G. Birch

\section{Introduction}

Piercings of the oral cavity has become increasingly popular amongst youth in western society, with some studies indicating a prevalence of $5.2 \%$ [1]. This popularity in certain fashion trends presents a growing problem for oral health professionals due to emerging evidence of its associated oral complications.

Gingival recession, tooth wear and fracture are the most frequently described complications of oral piercings [2,3]. Patients with tongue or labial piercings appeared to have the greatest incidence of such complications, particularly if they described a habit of knocking, biting or tapping of the piercing against the oral hard tissues [4,5]. Other oral complications include gingival inflammation, ulceration and periodontitis [5-8]. Although systemic complications are much more rare, the consequences of such complications can result in significant morbidity and mortality. These complications include Ludwig's angina, anaphylaxis, cerebral abscess, endocarditis, and hepatitis/HIV infection $[5,9]$.

This case describes a periapical lesion of tooth 41 associated with a large metallic tongue piercing, a complication which to our knowledge, has not been described in the literature previously.

\section{Case description and results}

A 29-year-old female presented complaining of an extruded and mobile tooth 41 (Figure 1). Patient first noticed the tooth was slightly extruded over a year ago and was concerned about it becoming increasingly mobile since. She denied any pain or symptoms associated with the tooth. Patient could not recall any history of trauma though mentioned she had worn a large metal tongue piercing for the past 11 years (Figure 2). Although she denied any habit of biting or tapping of the piercing against the teeth, she stated that it would occasionally hit the lower anterior teeth when moving her tongue or brushing her teeth.

Clinical examination revealed grade two mobility of tooth 41 . The buccal and lingual gingival mucosa were slightly inflamed and displayed $5 \mathrm{~mm}$ of recession on the buccal surface, and $6 \mathrm{~mm}$ of recession on

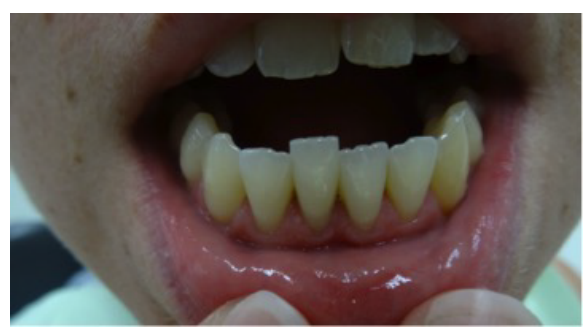

Figure 1. Extruded and mobile tooth. the lingual surface. A wear facet was evident on the cingulum area of tooth 41 . There was no evidence of any caries, cracks, fractures or discolouration. The tooth was not tender to percussion and thermal testing revealed a sluggish yet positive response to cold stimuli.

A periapical radiograph was taken showing large periapical radiolucency associated with tooth 41 (Figure 3). Overall the alveolar crest appeared intact.

The radiographic and clinical findings suggested that the periapical lesion was of endodontic origin. The large metallic barbell was determined to be the causative agent of the dental injury.

The first and perhaps most important step in treatment was removal of the underlying cause. After careful explanation of her diagnosis and the risks of the oral piercing, the patient was happy to remove it. Root canal therapy was then completed on tooth 41 and the patient asked to return for review in 3 months.

\section{Discussion}

The development of gingival recession or tooth fracture following traumatic injury from an oral piercing has been well documented in the literature $[2,3]$. To our knowledge the formation of a periapical lesion

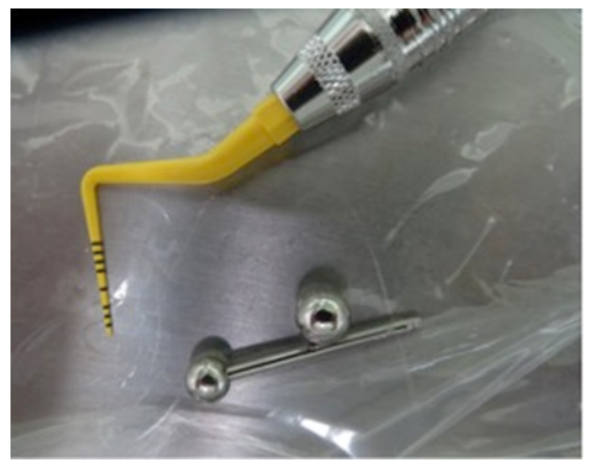

Figure 2. Large metal tongue piercing.

Correspondence to: Mehmet Oztel, James Cook University Dental Clinic 9 McGregor Rd, 0412491104 307/58-62 Ardisia St. Smithfield QLD 4878, Australia; E-mail: oztel.m@gmail.com

Key words: oral cavity, oral piercing, trauma

Received: February 15, 2016; Accepted: March 21, 2016; Published: March 24 2016 


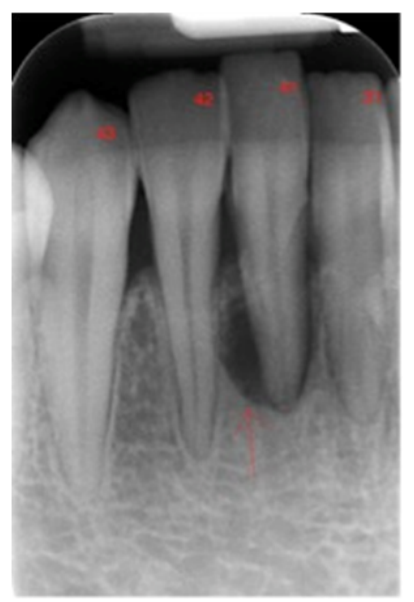

Figure 3. Large periapical radiolucency associated with tooth.

from the constant mechanical trauma of an oral piercing has not been reported before.

The literature suggests that the size of the piercing, the length of time it is worn and patient habits have the greatest influence on complications $[3,4,9,10]$. Although the patient did not describe any specific habits, she had a relatively large metallic tongue piercing for a period of 11 years.

The radiographic finding of a well-defined radiolucency of tooth 41 is suggestive of periapical lesion of endodontic origin. Although the tooth did not have any evidence of caries, restorations, cracks or fractures, there was evidence of a wear facet on the lingual surface that was likely caused by the oral piercing. Therefore it is likely that over time, the tooth suffered repeated traumatic insults from the large metallic piercing, rendering it non-vital.

Interestingly vitality and tenderness to percussion (TTP) testing appeared to be almost normal. Cold testing with Endofrost revealed a sluggish yet positive response in tooth 41 and the tooth was not TTP. Vitality testing with the cold test has a negative predictive value of 0.82 resulting in a $18 \%$ false positive rate [11]. Furthermore the chronic nature of the oral signs leads one to assume that degenerative and necrotic changes of the pulp are likely and that a slow positive cold test may indicate a partially necrotic pulp [12]. Chronic lesions may be asymptomatic with no tenderness to percussion [13] and frequently result in tooth mobility and extrusion [13].
This case highlights another complication brought on by the long-term use of large oral piercings. Examination of such patients should involve evaluation for any obvious signs of trauma and also for more subtle clinical signs like wear facets. These patients should be discouraged from wearing oral piercings and if not possible, oral health professionals should be prepared to provide information regarding the potential for complications and expensive dental treatment.

\section{References}

1. Hennequin-Hoenderdos NL, Slot DE, Van der Weijden GA (2012) The prevalence of oral and peri-oral piercings in young adults: a systematic review. Int J Dent Hyg 10: 223-228. [Crossref]

2. Hennequin-Hoenderdos NL Slot DE, Van der Weijden GA (2015) The incidence of complications associated with lip and/or tongue piercings: A systematic review. Int $J$ Dent Hyg 14: 62-73. [Crossref]

3. Giuca MR PM, Nastasio S, D' Ercole S, Tripodi D (2012) Dental and periodontal complications of labial and tongue piercing. J Biol Regul Homeost Agents 26:553-560. [Crossref]

4. Dirk Ziebolz AH, Proff P, Rinke S, Hornecke E, Mausberg RF (2012) Long-term effects of tongue piercing - a case control study. Clin Oral Investig 16: 231-237. [Crossref]

5. Maspero C, Farronato G, Giannini L, Kairyte L, Pisani L, et al. (2014) The complication of oral piercing and the role of dentist in their prevention: a literature review. Stomatologija 16:118-124. [Crossref]

6. Correa FO KM, Silveira FM, Martins TM, Ahmed HB, Javed F (2014) Severe alveolar bone loss around the mandibular incisor teeth as a long-term effect of tongue-piercing. J Coll Physicians Surg Pak 24: 375-376. [Crossref]

7. Escudero-Castaño N, Perea-García MA, Campo-Trapero J, Sánchez C, BasconesMartínez A (2008) Oral and Perioral Piercing Complications. Open Dent J 2: 133-136. [Crossref]

8. Kapferer I, Beier US (2012) Lateral lower lip piercing--prevalence of associated oral complications: a split-mouth cross-sectional study. Quintessence Int 43: 747-752. [Crossref]

9. Plessas A, Pepelassi E (2012) Dental and periodontal complications of lip and tongue piercing: prevalence and influencing factors. Aust Dent J 57:71-78. [Crossref]

10. Campbell A, Moore A, Williams E, Stephens J, Tatakis DN (2002) Tongue piercing: impact of time and barbell stem length on lingual gingival recession and tooth chipping. J Periodontol 73: 289-297. [Crossref]

11. Gopikrisha V, Pradeep G, Venkateshbabu N (2009) Assessment of pulp vitality. Int $J$ Paediatr Dent 19: 3-15. [Crossref]

12. Parolia A. Gait TC, Isabel C, Porto CM, Mala K (2013) Endo-perio lesion: A dilemma from 19 th until 21 st century. J Interdiscip Dent 3: 2-11.

13. Abbot PV (2004) Classification, diagnosis and clinical manifestations of apical periodontitis. Endod Topocs 8: 36-54.

Copyright: (C2016 Oztel M. This is an open-access article distributed under the terms of the Creative Commons Attribution License, which permits unrestricted use, distribution, and reproduction in any medium, provided the original author and source are credited. 